\title{
Mobilização e Articulação Comunitária do Canal Futura: institucionalização do monitoramento e avaliação
}

Carolina Misoreli ${ }^{1}$

Marisa Vassimon²

Rosalina Soares ${ }^{3}$
1 Canal Futura

2 Canal Futura

3 Fundação Roberto Marinho

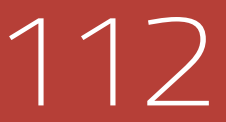

Em 2011, a área de Mobilização e Articulação Comunitária do Canal Futura contratou uma pesquisa exploratória avaliativa, no Brasil, com o objetivo de pré-testar indicadores de resultados, observando sua sensibilidade para a mensuração de fenômenos sociais, e verificar o alcance da atuação da área com as organizações sociais e redes parceiras.

A pesquisa ouviu mais de $60 \%$ das organizações sociais parceiras, combinando técnicas quantitativas e qualitativas em cinco frentes. Foi realizado survey com as organizações que são parceiras do canal nos últimos dois anos; survey com organizações que receberam maleta/kit contendo os conteúdos do canal; entrevistas em profundidade com dirigentes de redes; painel de especialistas para verificar a qualidade e a di- versidade das organizações parceiras relacionadas às cinco causas enfocadas pelo Canal Futura nos últimos anos.

A pesquisa aponta que o Canal Futura contribui para a disponibilização de informações de qualidade e plurais sobre as causas que aborda. O canal é considerado um grande aliado para o aprofundamento do debate em torno das causas, contribuindo para as atividades educativas das organizações sociais parceiras e para a diversificação de atuações, em especial com a expansão de novos meios educativos, como o audiovisual. As organizações apontaram a necessidade de o canal oferecer mais conteúdos que contemplem as diversidades regionais, ampliando, ainda mais, a pluralidade de pontos de vista sobre as causas. 


\section{Introdução}

O Canal Futura é um projeto social de comunicação de interesse público, mantido por empresas e fundações da iniciativa privada. Tem como missão contribuir, por meio da comunicação e da articulação social, para o desenvolvimento integral de pessoas e comunidades, sendo espaço de encontro e expressão de diferentes segmentos da sociedade. É comprometido com a transformação social e atua na tela, veiculando conteúdos de interesse público para todo o Brasil e nos territórios.

O canal conta com uma área denominada Mobilização e Articulação Comunitária, que atua presencialmente no território brasileiro, mediando diálogo com grupos sociais e organizações da sociedade civil, permitindo a disseminação e o uso do conteúdo do canal para além da tela da televisão. $O$ canal permite também a inclusão na tela de temas e abordagens na perspectiva de diferentes grupos sociais.

O monitoramento e a avaliação (M\&A) percorrem a história do Canal Futura, que realiza continuamente acompanhamentos, pesquisas e avaliações quantitativas e qualitativas. São realizadas pesquisas anuais sobre perfil do público e audiência, organizados grupos focais sobre programas e feitas avaliações sistemáticas de projetos especiais. Essa sistemática gera um círculo virtuoso para o canal, que planeja suas atividades, utilizando as informações das pesquisas e avaliações que realiza.

Os projetos realizados pela área de Articulação e Mobilização Comunitária do Futura contam com o seu próprio processo de M\&A. Contudo, em análises dos resultados desses estudos, sentíamos a necessidade de parâmetros que ajudassem a avaliar a área de Mobilização e Articulação Comunitária como um todo. Assim, no ano de 2011, realizamos uma série de oficinas com a participação de gerentes, coordenadores, analistas e mobilizadores para repactuar objetivos, resultados esperados, perguntas avaliativas, indicadores de processo e de resultados e meios de verificação. ${ }^{4}$

De acordo com Abbot and Guijt (1998) e Franco apud Brasil (2004), os benefícios de utilizar o monitoramento e a avaliação participativa podem ser resumidos em três aspectos: contribuir no processo de tomada de decisão e planejamento; prestar contas; e ressaltar as capacidades locais nos registros e nas avaliações dos processos de mudanças. Além disso, o requisito, para estruturar um monitoramento e uma avaliação participativa eficaz, é buscar responder à seguinte questão: para quem vai a informação e que benefícios irá trazer?

4 O histórico de reflexões do Canal Futura acerca de sua missão e objetivos - definido em anos anteriores - foi utilizado e considerado ponto de partida no processo de repactuação.

Revista Brasileira de Monitoramento e Avaliação | Número 4 | Julho-Dezembro de 2012 
No caso da área de Mobilização e Articulação Comunitária do Futura, o M\&A deve gerar informações que subsidiem a tomada de decisões dos gestores do Futura, visando aprimorar a atuação e tornar cada vez mais concretos e transparentes a atuação, os resultados e a contribuição social do canal.

Construiu-se uma matriz lógica, descrevendo objetivos, resultados esperados, perguntas avaliativas e indicadores, e também uma matriz de especificação, explicitando os indicadores, suas respectivas variáveis, meios de verificação e indicação de possíveis técnicas para apurar cada indicador. Em seguida, licitamos e contratamos a Overview Pesquisa para realizar uma primeira imersão dos indicadores nos territórios onde atuamos - pesquisa exploratória - em nível nacional, para verificar o comportamento dos indicadores e o alcance das ações da Mobilização e Articulação Comunitária do Futura com as organizações sociais parceiras. ${ }^{5}$

Os resultados da pesquisa foram apresentados para a equipe gerencial do Futura e demais profissionais da área de Articulação e Mobilização Comunitária do Futura em março de 2012 e estão sendo utilizados para planejamento de ações tanto em nível gerencial, quanto em nível de atuação com as organizações parceiras do canal. ${ }^{6}$
Realizou-se, ainda, como parte do processo de pesquisa, a análise crítica do comportamento dos indicadores e dos instrumentos de pesquisa, visando aprimorá-los para a realização de futuras pesquisas e avaliações.

\section{Escopo da pesquisa}

Pactuou-se como objetivos da área o fortalecimento e a articulação, o diálogo e a cooperação entre as diferentes formas de organização, representação e participação da sociedade brasileira e a visibilidade/ conhecimento de suas causas.

São esperados, a partir da atuação da área de Articulação e Mobilização Comunitária, os seguintes resultados:

- Organizações e movimentos sociais mobilizados, interagindo entre si e com o poder público e atuando em rede, em torno de causas e agendas;

- Conteúdos do Futura implementados com organizações, redes e parceiras;

- Conteúdos audiovisuais para tela/ web produzidos em diálogo e redes de produção;

- Públicos formados na produção audiovisual; e

- Tecnologias educacionais e sociais inovadoras realizadas e disponibilizadas. 
Para cada um dos cinco resultados foram elaboradas perguntas avaliativas e, consequentemente, um conjunto de variáveis e aspectos a serem considerados no momento de investigação. Como resultado, a área chegou a um quadro com 48 indicadores (processo e resultados), referentes a 24 conjuntos de perguntas avaliativas.

A pesquisa exploratória que apresentamos neste artigo focou esforços em dois resultados:

- Organizações e movimentos sociais mobilizados, interagindo entre si e com o poder público e atuando em rede, em torno de causas e agendas; e

- Conteúdos do Futura implementados com organizações, redes e parceiras.

A pesquisa destacou também oito indicadores de resultados:

- Qualidade do conjunto das organizações parceiras envolvidas nas causas trabalhadas pelo Futura/Mobilização por região e Unidade Federativa (UF), por tema;

- Qualidade do debate entre organizações e redes na atuação em torno das causas trabalhadas pelo Futura/ Mobilização: ${ }^{7}$
- Contribuição do Futura/Mobilização para a qualidade do debate entre organizações e redes, na atuação em torno de causas;

- Qualidade das ações com o poder público por parte das redes acompanhadas pelo Futura; contribuições do Futura para a qualidade das ações com o poder público;

- Contribuições do Futura para a ação das organizações;

- Uso dos materiais disponibilizados pelo Futura;

- Finalidade das práticas nas quais foram utilizadas os materiais do Futura; e

- Adequação dos produtos do Futura a públicos diferenciados.

Com base nas definições supracitadas, a Overview Pesquisa realizou estudo exploratório, no Brasil, com o objetivo de levantar insumos dos indicadores selecionados.

A Overview Pesquisa manteve diálogo constante com as equipes do Canal Futura e do núcleo de pesquisa e avaliação da Fundação Roberto Marinho, visando somar esforços para a construção de instrumentos de pesquisa sensíveis aos fenômenos sociais a serem pesquisados.

5 A Overview Pesquisa foi contratada no ano de 2011.

6 Ressaltamos que os resultados serão comunicados aos parceiros sociais nos territórios.

7 As causas pesquisadas: enfrentamento à exploração sexual infantil, promoção da saúde, promoção da participação da juventude, consumo consciente e direito à moradia.

Revista Brasileira de Monitoramento e Avaliação | Número 4 | Julho-Dezembro de 2012 


\section{Metodologia}

A pesquisa combinou técnicas qualitativas e quantitativas, desenvolvendo instrumentos para cinco frentes: entrevistas em profundidade com especialistas temáticos; entrevistas em profundidade com dirigentes de redes; grupos focais com beneficiários finais; survey com organizações parceiras do Futura nos últimos dois anos; e survey com organizações que receberam materiais do Futura.

\section{ENTREVISTAS EM PROFUNDIDADE COM ESPECIALISTAS TEMÁTICOS}

Essa modalidade foi aplicada para levantar insumos a fim de responder ao indicador "qualidade do conjunto das organizações parceiras envolvidas nas causas trabalhadas pelo Futura/Mobilização por região e UF, por tema". Entrevistaram-se 25 especialistas, cinco por causa/tema.

\section{ENTREVISTAS EM PROFUNDIDADE COM DIRIGENTES DE REDES}

Essa modalidade de pesquisa foi utilizada para explorar o indicador "qualidade das ações com o poder público por parte das redes acompanhadas pela Mobilização". Entrevistou-se uma amostra de trinta representantes das redes. O método de coleta foi entrevista presencial em profundidade, orientada por um roteiro semiestruturado.

\section{GRUPOS FOCAIS COM BENEFICIÁRIOS FINAIS}

Esses grupos tinham como objetivo levantar insumos para o indicador "adequação dos produtos do Canal Futura a públicos diferenciados". Para isso, a Overview realizou dez grupos focais em quatro estados/ cidades selecionados nas regiões geográficas atendidas, sendo quatro grupos focais em dois estados/cidades para cada um dos programas selecionados. O recorte adotado foi de amostra seletiva de participantes (cinco grupos focais com telespectadores engajados em causas sociais e cinco grupos focais com telespectadores "não engajados"). O instrumento utilizado foi um roteiro semiestruturado, visando avaliar especificamente a adequação dos produtos: pertinência da temática; clareza na apresentação da problemática; proximidade com o cotidiano; pluralidade de pontos de vista; adequação da linguagem; acessibilidade/empatia do formato; e disposição de uso/recomendação do material. Foram avaliados programas de televisão realizados pelo Futura com a colaboração de jovens ou organizações da sociedade civil.

\section{SURVEY COM ORGANIZAÇÕES PARCEIRAS NOS ÚLTIMOS DOIS ANOS}

Essa modalidade foi aplicada para levantar insumos para três indicadores: "qualidade dos debates entre organizações e redes na atuação em torno das causas trabalhadas 
pela mobilização"; "contribuição do Canal Futura para a qualidade dos debates entre organizações e redes na atuação em torno das causas trabalhadas pela mobilização"; e "contribuições da Mobilização/Canal Futura para a ação das organizações". Para isso, investigou-se uma amostra de 540 organizações, estratificada por causas sociais e representativas do universo de 1.027 instituições, com 4,2\% de margem de erro para estimativas de proporção. 0 método de coleta foi entrevista telefônica, orientada por um questionário estruturado, com representantes das instituições.

\section{SURVEY COM ORGANIZAÇÕES OUE RECEBERAM MATERIAIS DO FUTURA}

Essa estratégia foi utilizada para levantar insumos para os dois indicadores: "uso dos materiais disponibilizados pelo Canal Futura, por maleta/kit"; e "finalidade das práticas/ iniciativas nas quais foram utilizados os materiais disponibilizados pelo Canal Futura, por maleta/ kit". Para isso, investigou-se uma amostra de 331 organizações, estratificada por quatro tipos de maletas/kits e representativa do universo de 828 instituições, com 5,3\% de margem de erro para estimativas de proporção. O método de coleta foi entrevista telefônica, orientada por um questionário estruturado, com educadores, colaboradores ou representantes das instituições.

\section{Resultados}

\section{OQUALIDADE DO CONJUNTO DE ORGANIZAÇÕES PARCEIRAS ENVOLVIDAS NAS CAUSAS}

Por meio das entrevistas, pretendíamos compreender se Futura/Mobilização atua com as organizações e redes mais relevantes em relação às cinco causas definidas neste estudo e se efetivamente se articula com as organizações que mapeia como prioritárias.

Inicialmente, os especialistas descreveram quais são as características que consideram determinantes em um conjunto de organizações relevantes em cada uma das cinco causas. Depois da definição desses critérios, foi apresentada uma listagem de organizações parceiras engajadas na causa avaliada e sobre esse conjunto de instituições eles teceram comentários, identificaram a presença ou a ausência de entidades de referência no tema.

Para os especialistas, é notória a presença de organizações de referência nas cinco causas investigadas. Eles sugerem a aproximação com um número mais expressivo de universidades e a necessidade de equilibrar as parcerias geograficamente.

8 São redes que atuam em causas importantes para a área e com as quais a Mobilização se relaciona. Três delas de forma mais sistemática, e as outras de forma mais pontual.

Revista Brasileira de Monitoramento e Avaliação | Número 4 | Jullo-Dezembro de 2012 
QUUALIDADE DAS AÇÕES COM O PODER PÚBLICO POR PARTE DAS

REDES ACOMPANHADAS PELO FUTURA/MOBILIZAÇÃO

Por qualidade da ação com o poder público, compreende-se a capacidade de as redes e suas organizações estabelecerem com os organismos de Estado relações de representação, demanda e proposição, de controle social público e de complementaridade.

Foram trinta entrevistas em dez redes acompanhadas pelo Futura. Todas as redes analisadas participam de instâncias de diálogo, em maior ou menor número, a depender da abrangência da rede. Participam ativamente de reuniões, grupos de trabalhos, comissões e audiências, incidindo na apresentação de propostas específicas da rede e também na construção conjunta de propostas com outras organizações e membros da sociedade civil que frequentam os mesmos espaços de diálogo. A maioria participa diretamente de conselhos de políticas públicas. Nos conselhos, essas redes participam da elaboração e construção de propostas de forma conjunta de acordo com a dinâmica de cada conselho, e por isso não se tem informação da quantidade de propostas apresentadas.

São poucas as redes avaliadas com ações diretamente voltadas para políticas públicas quanto ao monitoramento, ao acompanhamento, à divulgação ou à melhoria da qualidade do serviço público. Muitas se envolvem com ações de mobilização da sociedade civil em geral, com foco na formação de agentes de transformação que possam posteriormente incidir sobre as políticas públicas. Nesse aspecto, podemos considerar que é uma ação indireta em relação à efetivação de políticas.

\section{CONTRIBUIÇÕES DO FUTURA PARA A QUUALIDADE DAS AÇÕES COM O PODER PÚBLICO E PARA AS AÇÕES DAS ORGANIZAÇÕES}

As próprias redes, com exceção da participação constante em conselhos, incidem no poder público de forma indireta. E a maior parte dos entrevistados considerou que existe impacto das contribuições da mobilização do Futura para as ações das redes com o poder público, também de forma indireta.

O acompanhamento realizado pelos mobilizadores de atividades das organizações e redes, assim como de fóruns e conselhos locais, legitima-os perante as entidades para a parceria entre elas e o canal. Sua presença em reuniões e atividades é considerada essencial para que a produção do canal possa de fato representar as agendas das causas trabalhadas por cada rede.

As redes percebem no canal um parceiro importante para a divulgação de suas ações e de suas agendas políticas, e com isso esperam um ganho até mesmo de manutenção da própria rede. Outro aspecto importante da parceria é a produção conjunta de materiais, que permite a autoexpressão das comunidades trabalhadas, assim como o trabalho de educomunicação na produção dos vídeos.

É bastante relevante para as redes de jovens a presença constante do canal nas ati- 
vidades dos encontros regionais de juventude e nas próprias conferências nacionais. Nesses momentos, há o reconhecimento de que o próprio canal vem ajudando na mobilização, articulação e divulgação das redes, configurando-se, neste caso, como uma excepcionalidade de contribuição direta do Futura nas ações de rede.

As maletas/ kits 9 e programas do Canal Futura são reconhecidos como os principais instrumentos de parcerias com as organizações. Também foram mencionadas, como expressão de parceria, as participações pontuais no programa "Conexão Futura"10 e a utilização das "Salas Futuras"11 de Pernambuco e Minas Gerais.

As organizações apontaram ainda que a parceria (Futura e organizações da sociedade civil) é importante no fortalecimento do debate de temas relevantes para políticas públicas no Brasil. As redes apontam, sobretudo, o fortalecimento de algumas ações da Mobilização: troca entre o conhecimento e profissionalismo técnico do canal e a experiência das redes para a sugestão de pautas importantes para a tela do Canal Futura.

\section{ADEOQUAÇÃO DOS PRODUTOS DO FUTURA, REALIZADA EM DIÁLOGO COM JOVENS E ORGANIZAÇÕES DA SOCIEDADE CIVIL, A PÚBLICOS DIFERENCIADOS}

Os resultados obtidos por meio dos grupos focais com beneficiários finais responderam ao indicador sobre a "adequação dos produtos do Futura a públicos diferenciados". Houve uma forte identificação dos jovens com o programa "Diz Aí", que foi muito bem avaliado, sobretudo por tratar da temática da juventude de forma plural e com uma linguagem simples e dinâmica ${ }^{12}$.

A temática "sexualidade" foi considerada uma das mais importantes de ser trabalhada, por ser muito presente no cotidiano (com forte apelo televisivo) e muitas vezes tratada de forma preconceituosa pela mídia. A temática "comunicação" foi ressaltada como elemento constitutivo da interação da juventude e a temática "juventude rural" foi a que mais chamou a atenção, por apresentar uma realidade desconhecida para a maioria.

9 O Canal Futura distribui conteúdos audiovisuais organizados em maletas Futura ou kits. Já foram criadas as maletas "Beleza" (2006), "Meio Ambiente" (2007), "Democracia" (2008) e "Saúde" (2009) e os kits "Consumo Consciente" (2010) e "Que Exploração é essa?" (2010).

10 Programa que ocupa as tardes do Canal Futura com entrevistas ao vivo.

11 Espaço com midiateca que disponibiliza, gratuitamente, o acervo audiovisual produzido pelo Canal Futura a serviço da educação e da defesa dos direitos humanos.

12 O "Diz Aî" é uma série de programas de curta duração que abordam temáticas relacionadas à juventude. A série é produzida de forma dialogada com os jovens.

Revista Brasileira de Monitoramento e Avaliação | Número 4 | Jullo-Dezembro de 2012

Mobilização e Articulação Comunitária do Canal Futura: institucionalização do monitoramento e avaliação 
Os episódios Sexualidades e Juventudes e comunicação foram os que receberam mais críticas em relação à clareza. No primeiro, foram tratados assuntos polêmicos e complexos - aborto, doenças sexualmente transmissíveis, gravidez na adolescência, orientação sexual - de forma muito ampla e rápida. O segundo ficou restrito a uma localidade do País e não abordou as principais formas de comunicação utilizadas pelos jovens.

A maior parte dos jovens considerou que os episódios do "Diz Aí" apresentam pluralidade de pontos de vista. Contudo, sentiram falta de alguns extratos sociais da juventude, como jovens mães no episódio da sexualidade, ou indígenas e jovens pobres do Nordeste no episódio que tratou de juventude rural.

A linguagem do programa foi considerada bastante adequada ao público jovem. No entanto, apontou-se a falta de acessibilidade para portadores de necessidades especiais. O formato do programa rápido, dinâmico e sem narrador foi o grande diferencial apontado positivamente pelos participantes dos grupos. O título "Diz Aí" foi identificado com a proposta de um programa que de fato dá voz aos jovens.

Os participantes consideraram que o "Diz Aí" estimula o debate e a mobilização, sobretudo no espaço das escolas e em oficinas com jovens.

$$
\begin{aligned}
& \text { OUALIDADE DOS DEBATES ENTRE } \\
& \text { ORGANIZAÇÕES E REDES NA } \\
& \text { ATUAÇÃO EM TORNO DAS CAUSAS }
\end{aligned}
$$

Os resultados obtidos por meio de entrevistas telefônicas com dirigentes das organizações responderam ao indicador sobre a qualidade dos debates entre organizações e redes na atuação em torno das causas trabalhadas pela Mobilização. Os entrevistados qualificaram os significados atribuídos à qualidade do debate, fortemente associada à consistência técnica, respaldada em conhecimento científico baseado em dados e pesquisas, e à consistência política, prevalecendo o conhecimento legal da causa.

Nesse indicador, a proposta era responder às perguntas: as organizações/redes conseguiram atuar de forma mais integrada? As organizações/redes estão lidando melhor com a diversidade de opiniões, visões e posições?

Na percepção dos dirigentes das organizações, a situação atual apresenta um cenário propício ao bom debate: $62 \%$ identificaram a existência de informações consistentes em torno do tema avaliado; $88 \%$ tinham acesso às informações e às análises consistentes. As fontes de informações mais citadas foram a internet (58\%) e os programas televisivos (31\%), entre eles os programas do Canal Futura.

\section{CONTRIBUIÇÕES DO FUTURA/ MOBILIZAÇÃO PARA OUUALIDADE DO DEBATE ENTRE ORGANIZAÇÕES E REDES NA ATUAÇÃO EM TORNO DAS CAUSAS}

Esse indicador dialoga com o indicador anterior e visa responder às perguntas: as redes com as quais o Futura se relaciona se fortalecem com a entrada do Futura? 
De que maneira a mobilização contribui para o fortalecimento e a atuação em redes em prol de causas e agendas? Como isso se dá em relação aos diferentes tipos de organizações e redes, temas e causas?

A percepção dos dirigentes das organizações sinaliza para um alto grau de contribuição do Futura nesse indicador. O canal é reconhecido pela maioria das instituições: por 96\% na divulgação de informação, por 94\% na formulação de argumentos consistentes sobre as causas e por 78\% na elaboração e disponibilização de informações de qualidade.

De acordo com a pesquisa, o Futura vem contribuindo significativamente para a consistência técnica e política do debate em torno das cinco causas pesquisadas, fomentando espaços para discussões e contribuindo para a pluralidade de pontos de vista.

\section{CONTRIBUIÇÃO DO FUTURA PARA AS AÇÕES DAS ORGANIZAÇÕES}

Os dirigentes de redes percebem que a parceria com o Futura/Mobilização contribui significativamente para a ação das organizações, tanto internamente, na formação do quadro pessoal, quanto na relação com outras organizações e redes. Ressalta- mos que em todas as regiões do País as contribuições percebidas são elevadas, mas há um especial destaque para as regiões Norte e Nordeste, sobretudo na causa "enfrentamento à exploração sexual infantil".

Na opinião dos dirigentes de redes, o Futura/Mobilização contribui para a ampliação do público atendido (69\%), a diversificação desse público $(65 \%)^{13}$ e o aumento da qualidade dos projetos (73\%). Em relação ao modo de atuação, o canal colabora em especial com o fomento para a utilização de audiovisual, sobretudo nas regiões Norte e Nordeste (63\%); com o estabelecimento de novas parcerias (77\%) e a inserção em novas redes (50\%); e com o desenvolvimento de novas metodologias (84\%), entre outras contribuições.

\section{USO DOS MATERIAIS DO FUTURA}

Os resultados obtidos por meio de entrevistas telefônicas com educadores, colaboradores ou dirigentes das organizações responderam sobre o uso dos materiais disponibilizados pelo Canal Futura, como a maleta Futura ou o kit. Nesse indicador, a intenção era saber se os conteúdos do Futura são utilizados e, se sim, com que frequência. Foram contatadas organizações que receberam a

13 Na causa "enfrentamento à exploração sexual" a porcentagem de dirigentes que associou a parceria do Futura à ampliação do público foi maior: $73 \%$.

Revista Brasileira de Monitoramento e Avaliação | Número 4 | Jullo-Dezembro de 2012 
maleta Futura ${ }^{14}$ e as organizações que receberam os kits "Consumo Consciente"15 e "Que Exploração É Essa?". 16

Avaliando o kit de uma maneira geral, mais da metade atribuiu nota 10 e apenas $6 \%$ nota inferior a 8 . Foram avaliados sete quesitos (conteúdo, estratégia de abordagem, adequação da linguagem utilizada, atualidade das informações, apelo audiovisual, praticidade de manuseio, adequação das sugestões de uso) e todos receberam conceitos "bom" e "excelente" da maioria das instituições (entre 92\% e 97\%). Todos os entrevistados reconhecem haver alinhamento do conteúdo dos kits recebidos com os interesses das instituições e cerca de $60 \%$ afirmam que o conteúdo está perfeitamente alinhado.

Os pontos fortes apontados nos kits foram "qualidade no audiovisual e na linguagem" (55\%) e "conteúdo" (48\%). Entre as fragilidades citadas: 15\% dos entrevistados apontaram o número insuficiente de maletas recebidas pelas instituições; $9 \%$ ressaltaram a falta de capacitação; 2\% destacaram a falta de monitoramento; e $25 \%$ salientaram a necessidade de apresentar conteúdos mais regionalizados.

Sobre a frequência de uso, 55\% afirmaram usar o kit/maleta semanal ou mensalmente e $40 \%$ utilizam-no esporadicamente. Já o kit "Meio Ambiente" é utilizado semanal ou mensalmente por cerca de $42 \%$, e a diferença na utilização semanal entre o Norte e o Nordeste foi de $8 \%$ e $20 \%$, respectivamente. Nas instituições, 94\% dos entrevistados afirmam haver outros colaboradores que utilizam o kit/maleta, e em $81 \%$ dessas instituições existem mais de três colaboradores que utilizam o kit, confirmando a disseminação do material.

No geral, 71\% dos entrevistados apontaram os alunos da educação formal como o público-alvo para utilização do material.

\section{FINALIDADE DAS PRÁTICASI INICIATIVAS NO USO DOS MATERIAIS DO FUTURA}

Neste tópico, queremos identificar as "agendas concretas/lutas/bandeiras" que orientaram/presidiram a utilização das maletas e kits. A finalidade se diferencia do "tipo de uso" (natureza específica das atividades em relação a determinado público).

Sobre a finalidade de utilização, a disseminação do conhecimento foi apontada por 58\% dos entrevistados. Entretanto, a resposta que prevaleceu no kit "Consumo Consciente" foi "trabalhar com conteúdos interdisciplinares em sala de aula", apontada por $68 \%$ das instituições.

Dos respondentes, 69\% afirmaram utilizar os conteúdos das maletas/kits em sensibilização. O segundo ponto mais citado foi "aulas na educação formal"; contudo, esse item no kit "Consumo Consciente" foi citado por $75 \%$ e no "Meio Ambiente", por apenas 29\% dos entrevistados. As cinco principais respostas espontâneas foram, em ordem: complementação/enriquecimento do conteúdo pedagógico; formação/educação; sensibilização/conscientização; aprofundamento/aperfeiçoamento dos conhecimentos; e mobilização. 
Sobre a perspectiva das finalidades mencionadas comparadas com o resultado esperado, 96\% apontaram que o kit ajudou em alguma medida no estabelecimento das metas. Nesse sentido, o kit contribuiu para alcançar o planejamento da agenda de discussões segundo 91\% dos entrevistados. Para $49 \%$, o material ajudou significativamente na construção de argumentos, sobretudo no Nordeste, onde alcançou 56\%. O kit contribuiu para alcançar a meta segundo 93\% dos entrevistados, inclusive ajudando significativamente, pois em $63 \%$ das respostas houve a contribuição na construção do debate sobre o tema. Este resultado foi ainda maior para o kit "Consumo Consciente", que alcançou 71\%. E 89\% consideraram que faria diferença uma atuação direta da equipe de Mobilização para utilização das maletas, uma vez que $87 \%$ dos entrevistados apontaram uma ajuda significativa do material.

\section{Conclusões}

Esta pesquisa foi um importante exercício para o Futura/Mobilização. Primeiramente porque houve planejamento participativo, que permitiu o envolvimento dos profissionais, de diversos níveis hierárquicos, em todas as etapas da pesquisa, permitindo uma apropriação e ação sobre os resultados encontrados. Também porque pré-testamos e amadurecemos, no chão dos territórios, indicadores e perguntas avaliativas, recém-formuladas, verificando se de fato respondiam ao nosso desejo de conhecer as contribuições do Futura/Mobilização para as causas trabalhadas e para as organizações e redes parceiras do canal.

O trabalho participativo, associado a uma exploração dos indicadores no território nacional, possibilitou momentos de reflexões sobre a relevância do monitoramento e da avaliação para projetos sociais comprometidos com a transformação social.

Nesse sentido, concluímos que a pesquisa, além de contribuir para ajustar o plano de trabalho do Canal Futura/Articulação e Mobilização Comunitária, trouxe diretrizes para o monitoramento frequente dos indicadores e para a modelagem de uma avaliação sistemática da área, compondo um círculo virtuoso de informações essenciais para o amadurecimento constante das ações do canal, tanto na tela da TV quanto nas ações presenciais nos territórios.

14 Kit formado por produtos audiovisuais do Canal Futura e de outras fontes (filmes, documentários, publicações, etc.) com ênfase em um recorte temático dos programas, valorizando o potencial provocador e reflexivo do acervo. Até 2011, foram produzidas maletas Futura com os temas: "Beleza" (2006), "Meio Ambiente" (2007), "Democracia" (2008) e "Saúde" (2009).

15 Kit, produzido em parceria com o Instituto Akatu e HP Brasil em 2010, composto por série de dez episódios sobre consumo consciente e sustentabilidade ambiental e material impresso para uso pedagógico do kit

16 Kit produzido em parceria com a Childhood Brasil, em 2010, composto por série de cinco episódios sobre exploração sexual infantil e material impresso com caderno de práticas com sugestões de uso do material audiovisual.

Revista Brasileira de Monitoramento e Avaliação | Número 4 | Jullo-Dezembro de 2012 